\title{
Public Institutional Structures for Disaster Preparedness in the Cereal Value Chain: A Zambian Case Study
}

\author{
Brigadier Libanda $(\mathbb{C}$
}

check for updates

Citation: Libanda, B. Public Institutional Structures for Disaster Preparedness in the Cereal Value Chain: A Zambian Case Study. GeoHazards 2021, 2, 352-365. https:// doi.org/10.3390/geohazards2040019

Academic Editors: Zhong Lu and Christopher Emrich

Received: 22 July 2021

Accepted: 17 November 2021

Published: 18 November 2021

Publisher's Note: MDPI stays neutral with regard to jurisdictional claims in published maps and institutional affiliations.

Copyright: (C) 2021 by the author. Licensee MDPI, Basel, Switzerland. This article is an open access article distributed under the terms and conditions of the Creative Commons Attribution (CC BY) license (https:/ / creativecommons.org/licenses/by/ $4.0 /)$.
Potsdam Centre for Public Policy \& Management, The University of Potsdam, August-Bebel-Straße 89 I Haus 7, 14482 Potsdam, Germany; brigadier.libanda@uni-potsdam.de; Tel.: +49-157-36704132

\begin{abstract}
Increasing extreme climate events and cyclonic activities provide clear evidence that the Southern African Development Community (SADC) region is a hotspot for climate change-driven natural disasters which critically disrupt agricultural production cycles. This is especially true with regard to the production of cereal, produce widely used to represent food security. Although studies have attempted to disentangle the effect of demand vis à vis projected population growth on cereal production across the region, the contradiction between cereal production and climate disaster preparedness remains poorly resolved. Therefore, literature on the subject matter is scanty. The present study is motivated by the need to overcome this paucity of literature and thus, deepen our understanding of cereal production and climate disaster preparedness in the region. Therefore, the main aim of this study is to assess public institutional support structures that are currently being employed for climate disaster preparedness in the cereal value chain across Zambia as perceived by small scale farmers. After a comprehensive assessment of focus group discussions (FGDs), several points emerge specifically highlighting four salient findings: first, results show that a governmentled Farmer Input Support Programme (FISP) is the only strategy particularly targeted at disaster preparedness. All other initiatives are targeted at improving or safeguarding livelihoods with some components having a ripple effect on the cereal value chain. Second, results show that climate forecasts that are supposed to trigger early action are generally characterized by low prediction skill with more false alarms and misses than hits. Third, forecasts were found to lack geographical specificity with generalities over large areas being common thus, diminishing their usefulness at the local scale. Fourth, end-users found forecasts to usually contain technical jargon that is difficult to decipher especially that most small-scale farmers are illiterate. This study concludes that to fully support the cereal value chain and realize food security in Zambia, policy formulation that champion the establishment of an effective early warning and early action system (EWEAS) involving multiple interest groups and actors should be considered a matter of urgency.
\end{abstract}

Keywords: climate change; adaptation; food security; institutional capacity; governance

\section{Introduction}

\subsection{Setting the Scene}

With 237 million people suffering from enduring undernutrition, the throes of hunger across the Southern African Development Community (SADC) region have reached recordbreaking levels [1]. A recent analysis has intimated that food insecurity rose by $10 \%$ in 2020 alone with over 44 million people being added to the list of chronically undernourished people [2]. With the novel COVID-19 pandemic undoing years of progress, most households have food consumption gaps (Integrated Food Security Phase Classification-IPC Phase 3) while others are facing emergency (IPC Phase 4). Projections indicate a 25\% increase in acute malnutrition across the SADC region by the end of 2021 [2]. Conditions are deteriorating across the region and millions are already facing acute food insecurity.

This brings into question the ability of the region to end hunger, achieve food security, and improve nutrition. The hunger situation has been attributed to economic disarray 
aggravated by extreme climate events. The frequency and intensity of these events in the face of a changing climate are projected to increase [3], therefore, challenging cereal production which is widely used to represent other major food crops and thus, a key indicator of food security [4]. Cereal production and agriculture, in general, are considered by the United Nations as pivotal to poverty alleviation across the region [5]. To this end, research on cereal production across SADC is a crucial area of scientific and policy inquiries; its fuller understanding deepens our knowledge of food security across the region.

Weather and climate are among the most important resources in the world. They support agriculture, socio-economic development, and boost the sustainability of both human life and ecosystems. However, extreme weather events, such as floods and droughts, are known to exert disasters on societies and to dictate economic rhythms especially in the SADC region where economies are mainly driven by rainfed agriculture. There is overwhelming scientific evidence, e.g., [6,7]. that disasters related to extreme precipitation events are already increasing across the SADC region. For example, in 2017, 44 people died and 79,000 were left homeless in Mozambique following the January extreme precipitation the country experienced and during the same rainy season, over 35,000 people were affected in neighboring Malawi and before the close of the season, Zimbabwe also experienced severe floods across 37 districts which extensively damaged infrastructure and forced transportation to be suspended [8].

All these climate shocks show that a mechanism that can effectively respond to them is urgently required. In the SADC region, responses to climate-related disasters such as cyclones, droughts, and floods have mainly been post-disaster; natural disaster insurance plays a significant role in this case [9-11]. However, ensuring that mechanisms to cushion climate-related disasters are put in place before they happen remains crucial and this has led to region-wide campaigns, e.g., Pieterse et al. [12] for the development of frameworks for adaptation planning and quantification of current and potential barriers to actualization. However, empirical research evaluating adaptation activities especially in the cereal value chain has been purely anecdotal. Therefore, there is a general lack of understanding of the extent, aims, and impacts of adaptation activities in the cereal value chain across the SADC region. This gap, if filled, would facilitate practice and pinpoint useful areas for future research lines.

The present study focuses on Zambia, a country in the SADC region (Figure 1). Zambia was chosen because of its high reliance on rainfed cereal production and would thus, provide indispensable insights. Evidence suggests that $66 \%$ of the labor force in Zambia uses agriculture as a primary means of livelihood with $78 \%$ of this figure being women farmers. Overall, agriculture is documented to account for $20 \%$ of Zambia's Gross Domestic Product [13]. Further evidence suggests that the most common cereal crops grown across Zambia are maize, sorghum, rice, wheat, and millet (bulrush and finger). Of these crops, maize is the dominant staple food [14].

Cereal production covers a landmass of 1.21 million hectares across Zambia [15]. Although there are inter annual variations in the size of land under cereal production, an increasing trend is generally evident especially from 1970 to 2018 [15]. FAO [16] attributes the observed variations in land under cereal production to seasonal rainfall changes and further argues that late onset of rainy seasons is the primary cause of contractions in area planted which almost always results in an equal effect on actual production.

Access to markets as the final part of the cereal value chain is generally characterized by private buyers who account for $80 \%$ of all maize sales among small-scale farmers [17]. In general, these private buyers visit rural communities and set up temporal trading centers to mainly buy maize. It is estimated that close to $50 \%$ of the total farm income of small-scale farmers is generated from maize which also accounts for $60 \%$ of the total area cultivated by small-scale farmers [17]. Considering that this estimate was done in 2011, its conceivable that it has now grown significantly. 


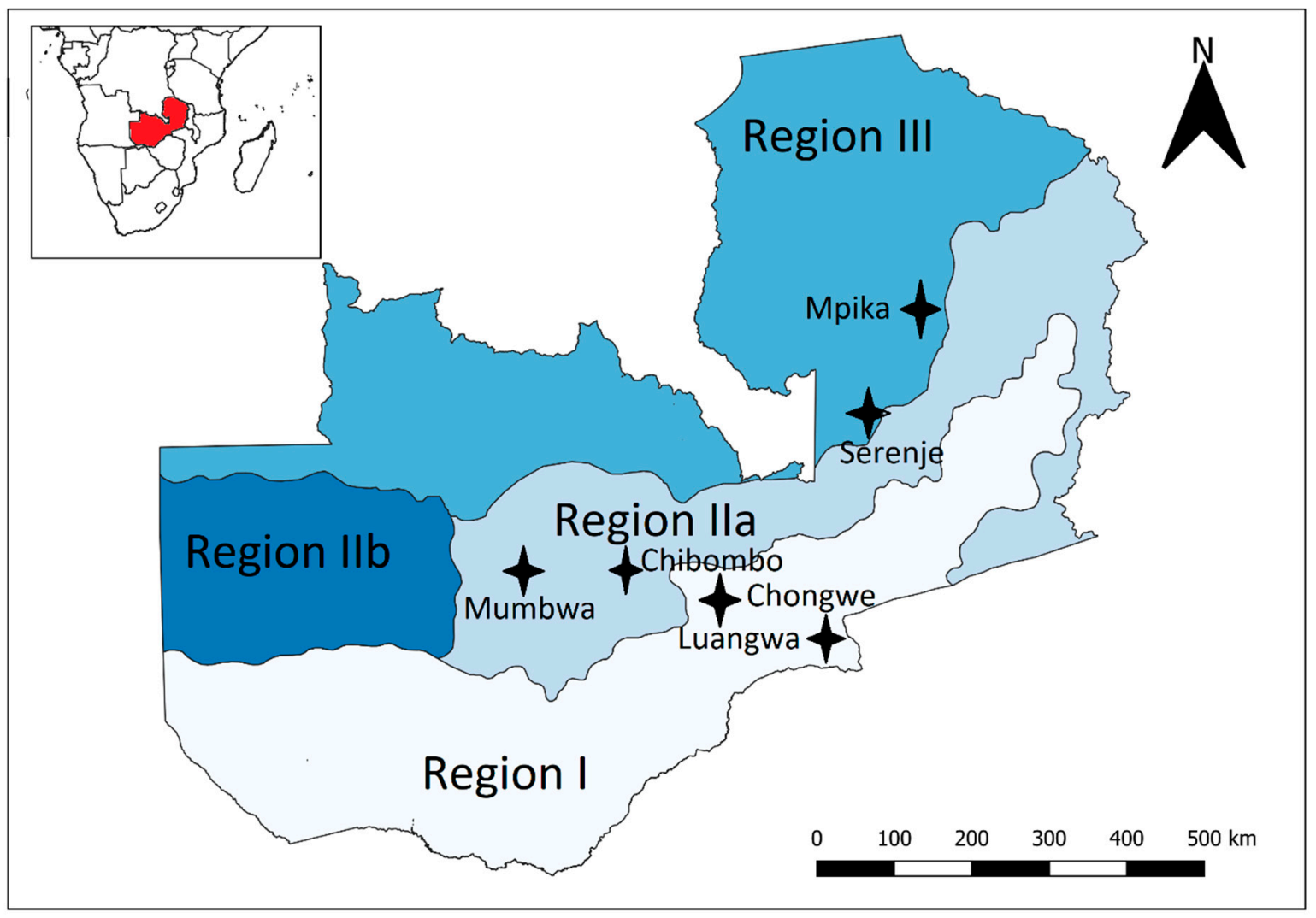

Figure 1. Map of the study area in Africa shown in red on the insert. Asterisks on the map of Zambia indicate data collection points. Shading in the map of Zambia shows respective Agroecological Regions.

Although Zambia is a major cereal producer, it also imports to fill deficits which often lead to food consumption gaps. The latest IPC acute food insecurity report shows that $\sim 1.73$ million people are currently facing food insecurity (IPC Phases 3 and $4 ;$ [18]). For the current marketing season, cereal imports are expected to be $\sim 74,000$ tonnes which translates to $\sim 15 \%$ above the five-year average [19].

Droughts and floods are the most common climate disasters that affect cereal production in Zambia with frequent and more intense rainfall deficits being widely cited as primary drivers of drought especially across the southern parts of the country [20,21]. For instance, during the 2018-2019 cereal production season, Zambia experienced prolonged dry spells which negatively affected crops and resulted in decreased cereal production especially across Southern province-a drought prone region. As a consequence of the 2018-2019 prolonged dry spells and concomitant reduction in cereal production, food stocks quickly became depleted in most households, leading to dependence on market purchases, thus causing the price of cereal, especially maize, to skyrocket [22]. In total, 192,000 people across Southern province alone were found to have major food consumption gaps thus classified as facing crisis, while 54,000 were at emergency levels according to IPC classifications.

In recent years, it is common for intense dry spells and floods to occur within the same season thus, critically affecting cereal production. For example, during the 2017/2018 season, intermittent dry spells and intense floods affected much of the country destroying large proportions of cereal crops especially wheat, sorghum, and maize [23]. This led to a $33.6 \%$ decrease in maize production compared to the previous season $(2016 / 2017)$ and a $20 \%$ decrease compared to the 5-year mean [22] leading to an estimated 2.3 million people being food insecure and pushing millions below the poverty line [24,25].

This study seeks to ask one important, yet presently poorly resolved research question: which institutional support structures are currently being employed for climate disaster 
preparedness in the cereal value chain across Zambia? Findings will contribute to underpinning management and strategic planning that aim to improve disaster preparedness and overall food security.

\subsection{Institutional Strategies for Climate Change Adaptation in the Cereal Value Chain}

Across the SADC region, climate change adaptation is an emerging policy and planning area. It refers to tangible efforts employed to reduce the risk and vulnerability of communities and properties [26]. Climate change adaptation is "the adjustment in natural or human systems in response to actual or expected climatic stimuli or their effects, which moderates harm or exploits beneficial opportunities" [26]. In line with this description, climate change adaptation has been closely associated with disaster preparedness, management, and climate resilience. Therefore, climate action plans are developed with the motivation of averting or reducing a country or region's vulnerability to climate changeinduced disasters at the local scale.

Understandably, sometimes climate change adaptation and disaster preparedness come from outside government, are unplanned, and can be wide-ranging [27]. However, the emphasis of this paper is on interrogating government-driven climate disaster preparedness with a focus on the cereal value chain, produce widely used to represent food security in the SADC region. Therefore, in this study, climate change adaptation/disaster preparedness is defined as the purposeful development, by the government, of strategies aimed at reducing the negative effects of climate change-driven disasters in the cereal value chain across Zambia.

\section{Materials and Methods}

\subsection{Study Area}

This study was designed to have representation from each of Zambia's three main agroecological regions (Figure 1). These regions are generally distinguished one from the other based on annual precipitation amounts and edaphic characteristics. It was, therefore, hypothesized in this study that differentiated experiences of farmers regarding climatic disasters and thus, available institutional support structures for disaster preparedness in the cereal value chain are possible. To capture evidence across the whole landscape, two study locations from each agroecological region were chosen.

Agroecological region zone I is generally characterized by semi-aridness. Mean annual precipitation ranges from 600 to $800 \mathrm{~mm}$ while the growing seasons are usually in the range of 80 to 120 days. This subjects crops grown to incessant dry spells. Topography does across the Region generally does not exceed $800 \mathrm{~m}$ above seas level. The region extends from the Southern, parts of Eastern, and Western Provinces of Zambia. In this study, Chongwe and Luangwa were picked as study points. The choice of these study points was influenced by distance from Lusaka.

Agroecological region zone II has the most fertile edaphic attributes and therefore, harbors the country's majority of commercial farmers. With mean annual precipitation amounts of $800-1000 \mathrm{~mm}$, agroecological region II is generally wetter than region I. it is also characterized by longer rainy seasons of up to 140 days in some years. The region covers some parts of Southern, Central, Lusaka, and Eastern Provinces. Here, Mumbwa and Chibombo were picked as study points.

Region III is generally considered a high-precipitation area. The region is the wettest across the country and receives mean annual precipitation of $>1000 \mathrm{~mm}$. The growing season lasts between 120 and 150 days. However, the Region's soil is generally considered unsuitable for farming because of its high acidity and poor nutrients. This region covers much of Northwestern, Copperbelt, Luapula, Northern, and some parts of Central Province. In this Region, Mpika and Serenje were used as study points. 


\subsection{Research Design}

\subsubsection{Focus Group Discussions}

The research design was adopted from the pragmatic approach of [28] who interrogated the role of institutions in climate change adaptation across Zimbabwe, and [27] who studied urban climate change adaptation planning in the United States.

In the first step, qualitative data were collected through six focus group discussions (i.e., two in each agroecological zone; Table 1). Focus groups consisted of only smallscale farmers which helped to ensure that results reflected institutional structures that were on the ground as opposed to promissory notes, i.e., those that were still at the planning stage. It was hypothesized that instituting focus groups comprising public service workers would likely lead to results biased towards planning and, therefore, fail to satisfy the objective of this work. On the other hand, having beneficiaries (i.e., small-scale farmers) ensured that results were representative of actual strategies on the ground and thus, gave farmers' perceptions with regard to institutions and their role in disaster preparedness across the cereal value chain. The focus groups were restricted to a maximum of 10 participants to ensure compliance to the set standards of social distancing due to the spread of SARS-CoV-2 [29]. These focus groups were created to guarantee a near equal representation of male, female, and age groups. This resulted in 49 participants compromising of 25 females, 24 males, and a median age of 35 . Although there is general scholarly unanimity on the importance of focus groups in qualitative research, controversies about how many participants are enough have raged unabated for a long time now. Several divergent accounts have been proposed [30], resulting in numerous controversies. However, one aspect on which consensus seems to be established is that anywhere from 5 to 50 participants is adequate [31]. Here, 49 participants were, therefore, considered adequate to satisfy the goal of this study.

Table 1. A summary of focus groups and main cereal crops grown.

\begin{tabular}{cccc}
\hline Agroecological Zone & District & Participants & Main Cereal Grown \\
\hline I & Luangwa & 8 & Maize, sorghum, and finger millet \\
I & Chongwe & 9 & Maize, sorghum, and finger millet \\
II & Mumbwa & 9 & Maize, soybeans, wheat, and sorghum \\
II & Chibombo & 10 & Maize, soybeans, wheat, and sorghum \\
III & Serenje & 7 & Maize and finger millet \\
III & Mpika & 6 & Maize, sorghum, and finger millet \\
\hline
\end{tabular}

Data collected were on (1) the types of cereal crops grown and their impacts on livelihoods (2) weather and climatic changes that affect cereal production, (3) traditional strategies used in safeguarding cereal production, and, finally, (4) institutions that contribute towards climatic disaster preparedness in the entire cereal value chain.

The environment of the focus group discussions was relatively comfortable and with all participants seated in a circle; consent was sort to record the interviews anonymously for analyses afterwards. Participants of focus group discussions (FGDs) were firstly asked to come up with a list of institutions that work in their area and their respective functions regarding disaster preparedness in the cereal value chain. They were also asked to describe how the identified institutions interact with the community and with one another. Participants were then asked to reach a consensus following intensive discussions on the performance of the identified institutions. Performance was rated out of 10 with 10 being a perfect score. The final scores were then used to rank the identified strategies used for disaster preparedness in the cereal value chain. Therefore, although FGDs are qualitative in nature, the analyses included deriving numerical-based statistics.

All the questions were open-ended, and every effort was made to avoid dichotomous ones. Therefore, the specific questions that were asked are as follows: (i) Which institutions work in your area? (ii) In what ways do the named institutions contribute to disaster preparedness in the entire cereal value chain? (iii) How do the identified institutions interact with one another? (iv) How do the identified institutions interact with the community? 
(v) With 10 being the highest score, how would you rate the performance of the institutions? On average, each FGD lasted for $1 \mathrm{~h}$ and $5 \mathrm{~min}$.

\subsubsection{Systematic Review}

The data collected from FGDs was then supplemented by a systematic literature review. Literature searches were done by adopting the pragmatic sampling procedure used by [32] who employed Clarivate Analytics' Web of Science (WoS; www.webofknowledge.com; accessed: 23 December 2020) to give an overview of climate change vulnerability. Web of Science is an online abstract and citation database that houses peer-reviewed literature and web sources of quality standing. It contains $>70$ million records across over $>10,000$ journals.

In the first step, to construct a robust pool of authoritative peer-reviewed literature and establish the current understanding of public institutional support structures for disaster preparedness in the cereal value chain, the search was not limited to Zambia. Therefore, the only search terms that were used are climate change, climate resilience, climate adaptation, cereal, and agriculture. To ensure that cereal and agriculture were captured in both climate change resilience and adaptation contexts, the first three terms (i.e., climate change, climate resilience, climate adaptation) were joined by an 'or' operator, while the last two terms (i.e., cereal, and agriculture) were joined by an 'and' operator. This search returned 532,588 articles. A perusal of these articles was done and the most relevant were picked to inform the context that has been used in the introduction and discussion of this paper.

In the second step, the results were refined by the term 'Zambia'. To capture both pioneering and recent understanding of existing public institutional support structures for disaster preparedness in the cereal value chain, 'Published: All years to present' was chosen. This search returned 535 articles with 1969 being the year of the first publication and 2021 the year of the most recent publication. These results were then screened with a bias towards capturing only articles published in English. The practice of considering only English-based works is widely used around the world [27]. Further, for articles to be included in this study, they had to be documenting or assessing institutional support structures or planning activities with relevancy to the cereal value chain in the confines of Zambia.

Information from both government and non-governmental organization reports were also used. This is because many organizations such as The Zambia Institute for Policy Analysis and Research (ZIPAR), a semi-autonomous Think-Tank, have published reports containing valuable information with relevance to climate change adaptation and disaster preparedness. However, care was taken to ensure that only unbiased sources were used. Therefore, any material from lobby, partisan, or advocacy organizations were not included as these are generally thought to represent the position of a given group and thus, biased [15].

\section{Results}

\subsection{Available Institutional Support Structures}

A case-study approach was chosen to allow a deeper insight into actual disaster preparedness strategies being received by smallholder farmers from public institutions, in the cereal value chain. Results from focus group discussions (FGDs) indicate that much of the institutional support is from technical organs of the Government of the Republic of Zambia (GRZ) with funding from international organizations (Figure 2). GRZ institutions that were repeatedly mentioned include the Disaster Management and Mitigation Unit (DMMU), the Zambia Meteorological Department (ZMD), the Ministry of Agriculture, together with its research institute (Zambia Agriculture Research Institute), and the Food Reserve Agency (FRA). 


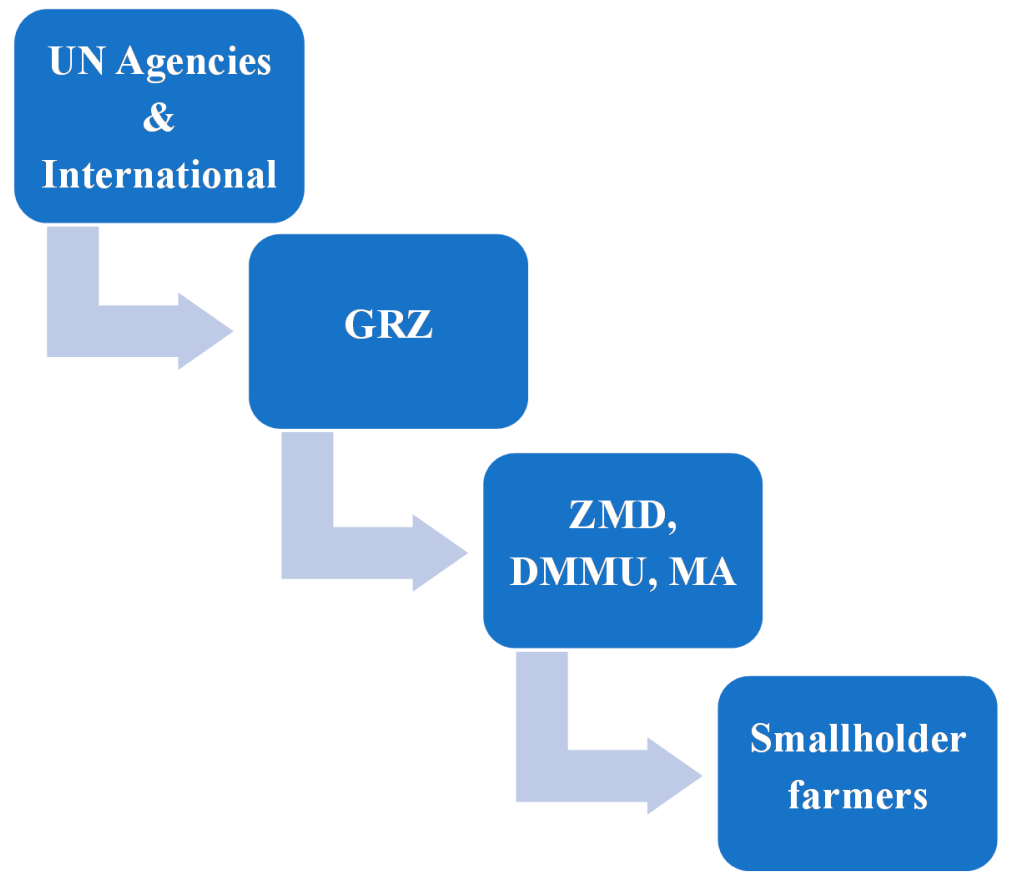

Figure 2. Institutional support structure providing climate disaster preparedness as perceived by smallholder farmers. UN, United Nations; NGOs, Non-Governmental Organizations; GRZ, Government of the Republic of Zambia; ZMD, Zambia Meteorological Department; DMMU, Disaster Management and Mitigation Unit; MA, Ministry of Agriculture.

International institutions that were perceived by smallholder farmers as having an active role in disaster preparedness in the cereal value chain include the United Nations Food Agriculture Organization, the United Nations Development Programme, the United Nations World Food Programme, the World Bank, World Vision International, and the Red Cross Society. One striking observation to emerge from this analysis is that the private sector was generally viewed by smallholder farmers as a provider of quick but non-competitive market after harvesting yet playing no role in disaster preparedness across the cereal value chain.

\subsection{Strategic Implementation}

Participants highlighted that of the identified institutions, much of the support received is in the form of access to farming inputs vis à vis a subsidy program through FRA (Table 2). If delivered on time, the inputs enable farmers to plant their cereal crops on time thus, potentially averting hunger all other conditions considered favorable. The evidence further suggests that the government-led Farmer Input Support Programme (FISP) is the only strategy particularly targeted at disaster preparedness in the cereal value chain. All other initiatives are targeted at improving or safeguarding livelihoods in general with some components having a ripple effect on the cereal value chain. In FISP, each smallholder farmer receives four $50 \mathrm{~kg}$ bags of fertilizer together with $10 \mathrm{~kg}$ bags of maize seed. FRA then provides a ready market for their produce. Although heavy focus has been placed on FISP by the government, FGDs revealed that not all smallholder farmers benefit from the initiative. In fact, it was reported that, in 2015 , only $56 \%$ of smallholder farmers benefited from FISP despite the program receiving $55 \%$ of the total agricultural budget [16]. 
Table 2. A summary of benefits received by smallholder farmers as part of disaster preparedness in the cereal value chain.

\begin{tabular}{ccc}
\hline Activities & Score/10 & Rank \\
\hline Access to farming inputs & 6 & 1 \\
\hline Access to relief & 6 & 1 \\
\hline Access to drought-resistant and early maturing crops & 5 & 2 \\
\hline Access to training in climate-smart technologies & 5 & 2 \\
\hline Access to weather and seasonal forecasts & 4 & 3 \\
\hline Access to increased extension services & 3 & 4 \\
\hline Access to climate-smart technologies & 2 & 5 \\
\hline Access to crop diversification opportunities & 2 & 5 \\
\hline Access to safe water points & 0 & 6 \\
\hline Access to post-harvest storage & 0 & 6 \\
\hline Access to cash-based safety nets & 0 & 6 \\
\hline Access to increased health service provision & 0 & 6 \\
\hline
\end{tabular}

Similar to farming inputs, accessibility to relief food was rated high (Table 2). Farmers generally cited DMMU as coming to their aid, especially in times of floods. Support received during these times includes food and temporal shelter. International NGOs such as World Vision International and the Red Cross were also repeatedly mentioned as being heavily involved in disaster preparedness, although not particularly focusing on climatic shocks.

Farmers considered some of the maize seeds received through the subsidy program as having some form of resistance to drought and thus, rated this strategy second together with access to training in climate-smart technologies. Farmers cited World Vision International as being instrumental in mobilizing them for training purposes. Zambia Agriculture Research Institute was also seen as supportive in training farmers but only when farmers made the effort to visit their offices.

Access to weather and seasonal forecasts was rated third (Table 2). Farmers cited local radio stations as being instrumental in the delivery of weather and seasonal forecasts generated by the Zambia Meteorological Department. One finding that particularly stood out was that interest in listening to forecasts had recently surged since the introduction of local language-based forecasts.

Participants rated access to extension services fourth. The poor rating of this service was attributed to the fact that much of the extension services are related to animal husbandry and control of livestock movements from one region to the other in a bid to limit zoonotic infections and livestock diseases. There were generally few extension services for cereal and crop farming in general.

Farmers cited access to crop diversification opportunities in disaster preparedness as being poor. They further classified increased access, during a climatic disaster, to safe water points, post-harvest storage, cash-based safety nets, and increased health service provision as generally being non-existent (Table 2).

In total, $49 \%$ of the participants regarded climate information as a key variable for disaster preparedness (Figure 3); 33\% found it extremely useful; 15\% somewhat useful; 3\% were unsure; and none said it was unnecessary. Respondents who found climate information useful noted that if there were indications of potential dry spells, this information was used to drill wells to access water contained in an aquifer and use it for irrigation purposes before the onset of dry spells or drought. However, such preparedness strategies were found to be only possible for small gardens. Therefore, for larger fields, climatic early warning information was used as a guide for determining planting dates. 


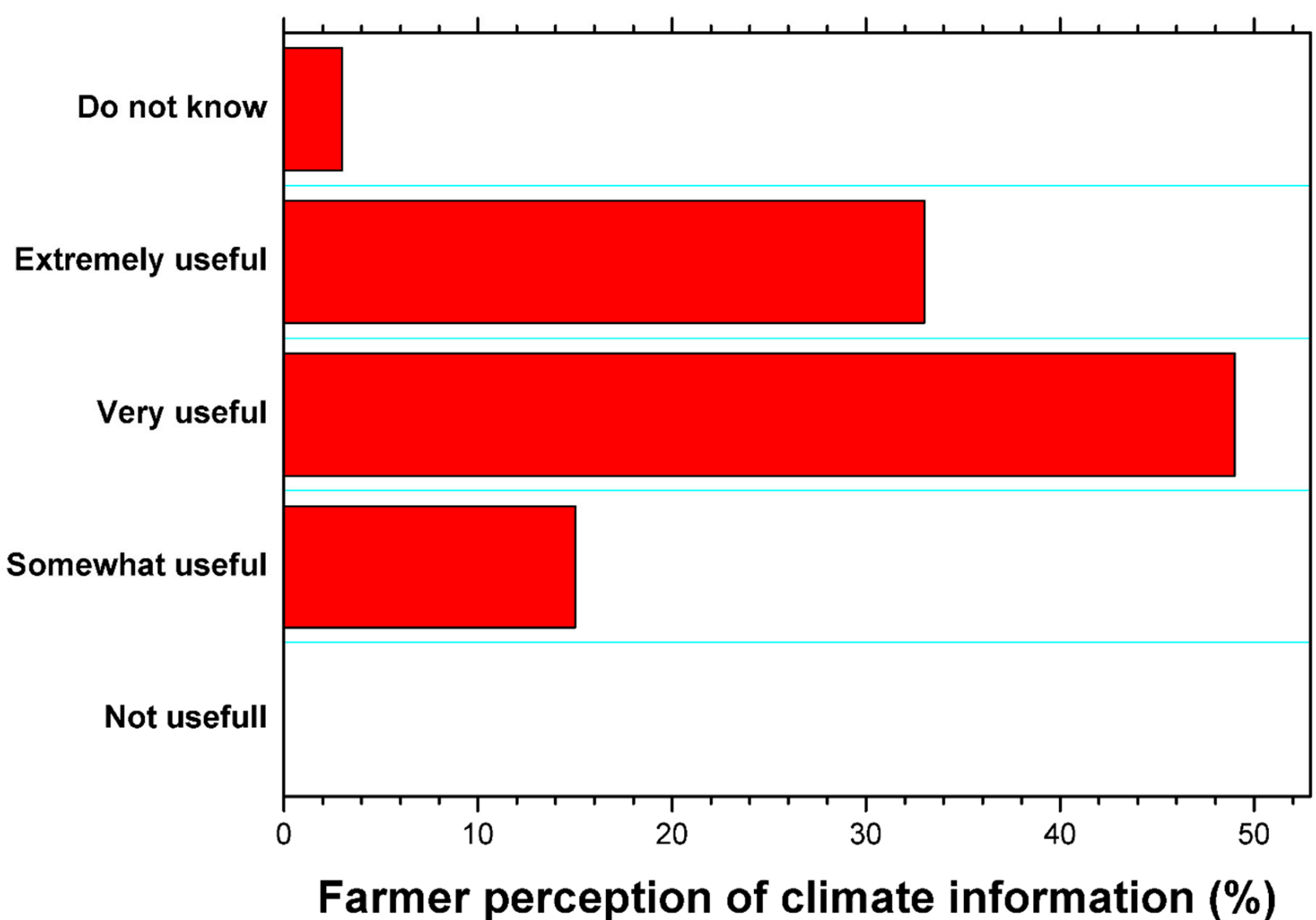

Figure 3. Small scale farmer perception of the importance of climate information for disaster preparedness in the cereal value chain.

Results from focus group discussions indicate that the source of climate information for disaster preparedness is mostly indigenous knowledge (Figure 4). However, interest in climate forecasts was found to vary before, during, and after the rainy season. Specifically, $60 \%$ of all climate information sources before onset of the rainy season, $60 \%$ during, and $44 \%$ after the rainy season was indigenous knowledge. Results further indicate that climate forecasting using indigenous knowledge heavily relies on biological and environmental indicators with traditional beliefs exerting equal influence. For instance, farmers cited heavy fruition of Rhus Lancea as an indicator of above-average rainfall, while in years that it produces few fruits, drought was to be expected. Above normal temperatures were also seen as an indicator of a potential wet year while an extended winter period was taken to be a forecast of a dry year. Although forecasting using indigenous knowledge has a long history, FGDs revealed that forecasting in this way is increasingly becoming difficult because of rapid climatic changes.

Forecasts from the Zambia Meteorological Department (ZMD) were until recently not frequently used for crop management decisions. Respondents cited low prediction skill, a lack of geographical specificity, and general difficulties in deciphering ZMD forecasts as major impediments. However, the recent issuance of these forecasts in their local languages through the media was cited as having encouraged a surge of interest although geographical specificity remains a challenge. 


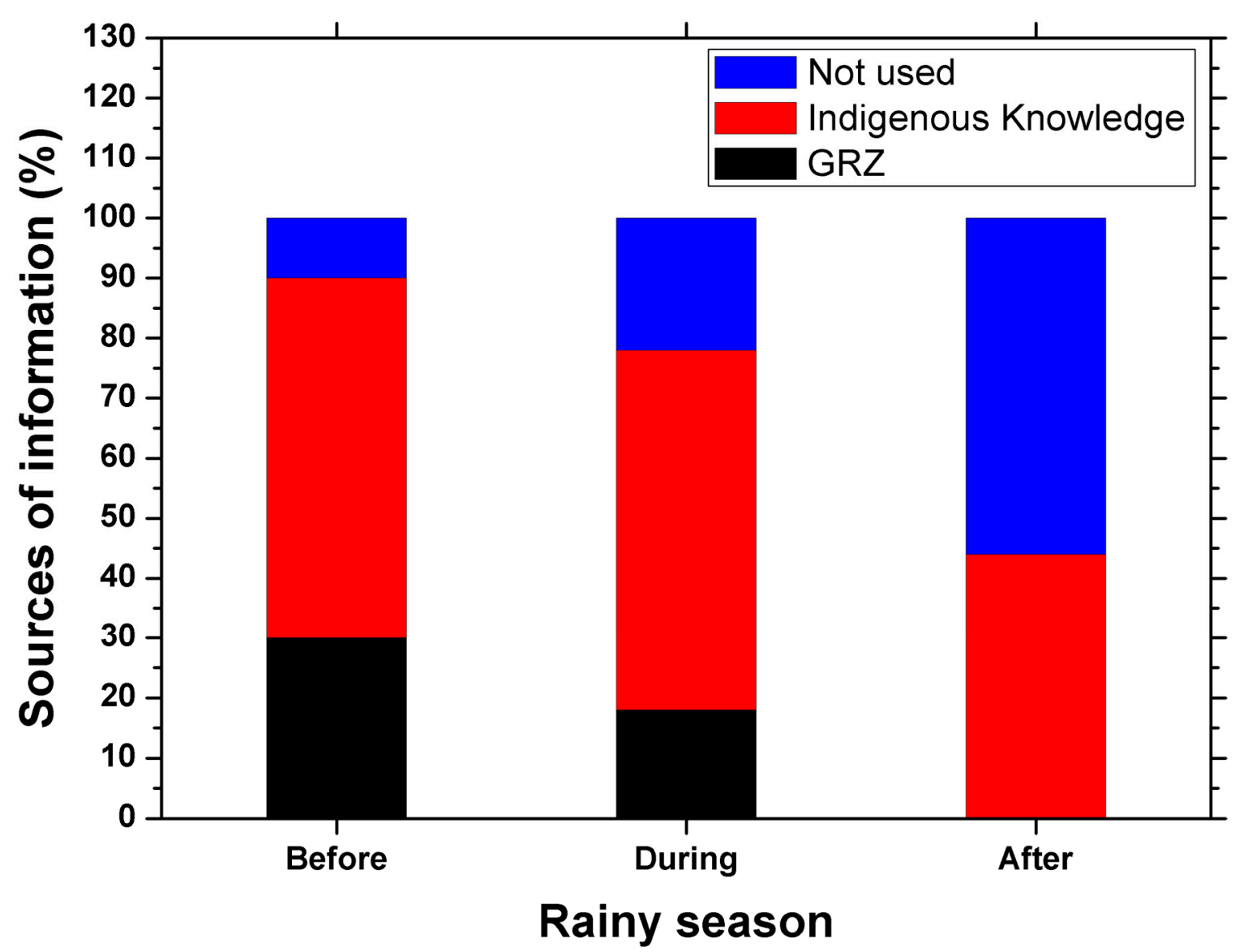

Figure 4. Sources of climate information used by respondents for disaster preparedness in the cereal value chain.

\section{Discussion}

\subsection{Available Institutional Support Structures: The Need for Early Warnings}

The present study was designed to determine public institutional support structures for disaster preparedness in the cereal value chain across Zambia. The most obvious finding to emerge from the analyses is that the government-led Farmer Input Support Programme (FISP) is the only strategy particularly targeted at disaster preparedness in the cereal value chain. All other initiatives are targeted at improving or safeguarding livelihoods as a whole with some components having a ripple effect on the cereal value chain.

FISP has to some extent contributed to Zambia's ability to produce enough maize for both local and regional consumption. For instance, during the 2011 and 2012 agricultural seasons, the country recorded bumper harvests of 2,795,483 and 3,020,380 metric tonnes, respectively, thus, translating into a surplus of $>1$ million metric tonnes [33]. Although the advantages of FISP are apparent, its emphasis on maize has contributed to overdependence on it at the detriment of other cereal crops and overall crop diversity. This introduces several drawbacks, first, it hurts nutrition thus, contributing to undernourishment [34]; second, FISP incentives have encouraged farmers to apportion more land to maize cultivation thereby reducing land left, e.g., for irrigation purposes and cultivation of other crops [35]; third, with climate change, floods, and droughts becoming frequent across Zambia [36]. As such, the agricultural landscape is changing in increasingly severe ways [37] thus, the FISP program may not be sufficient in the near future.

A recent study shows that when poverty levels were analyzed among populations that are most at risk of extreme climatic events such as floods, the largest numbers are in Sub-Saharan Africa. It was further found that $\sim 71$ million people are estimated to be in extreme poverty while at the same time highly at risk of floods across the region [37]. However, when such communities are linked to agrometeorological early warning systems, 
improvements in the production of cereal and overall food security are always recorded [16]. It can, therefore, be argued that coping with concomitant challenges posed by floods and droughts in the cereal value chain requires an effective early warning and early action system (EWEAS) as opposed to waiting for them to affect vulnerable communities. The early warning and early action system would thus, be thought of simply as disaster preparedness. In practice, such a system would go beyond the mere distribution of inputs. Instead, it would involve multiple institutions working together [38] and this has so far been found to be effective by the Famine Early Warning Systems Network (www.fews.net; accessed: 23 December 2020) across some parts of Africa. An EWEAS would start by the generation of an alert with geographic specificity and advance notice of ideally 3-6 months.

An EWEAS would be made effective by linking all alerts issued to contingency plans, actors, and specific funding instruments [39]. Acting early would potentially reduce humanitarian caseloads by protecting smallholder farmers from adopting negative coping strategies when a climatic disaster strikes. Evidence suggests that climatic shocks are one of the main causes of family separations which forces the most vulnerable to embrace otherwise unfavorable coping mechanisms [40]. Some of these mechanisms include early marriage arrangements and dropping out of school. Additionally, when families are separated, children and women become more exposed to exploitation, gender-based violence, and sometimes isolation from the much-needed humanitarian assistance [41].

Therefore, to fully support the cereal value chain and realize food security in Zambia, an effective EWEAS is necessary. There is a need to go beyond FISP. Additionally, since all EWEAS activities are based on the initial alert, investments in improving weather and climate forecasts are crucial [42], especially considering the observation that current forecasts are characterized by low prediction skill as observed also in Zimbabwe [28]. Based on forecasts, institutional support before a disaster strikes can include rehabilitation of water points or construction of irrigation infrastructure. Vulnerable smallholder farmers can be trained on alternative agricultural practices and livelihood options or provided with access to drought-resistant seeds that would guarantee them a harvest in case of, e.g., a drought. Other activities applicable to both floods and droughts may include increased health service provision, extension services, food- and even cash-based safety nets.

\subsection{Strategic Implementation: Triggering Early Action}

Forecast triggers that would dictate when to act should ideally be agreed in advance by all stakeholders. Potential public institutions that can be involved here include the Zambia Meteorological Department, the Disaster Management and Mitigation Unit, and the Ministry of Agriculture.

Funding is also required to implement the agreed actions when a forecast trigger is set off. Just like with forecast triggers, the mechanism by which this funding is released must be agreed upon among all stakeholders way before the need arises [39]. For effective planning and implementation purposes, a platform for dialogue supported by government policies or a legal framework within which the coordination of the system happens is necessary. This platform can also be used for retrospective analyses and using findings to model likely outcomes well in advance of a climatic disaster happening.

The establishment of a platform for dialogue is especially necessary for the framing of climate disaster preparedness strategies. Here, it is hypothesized that governmentdriven arrangements and partnerships that support climate disaster preparedness in the cereal value chain will dictate the setting of priorities. This hypothesis is supported by the Cultural Theory of Risk which postulates that the feasibility of climate change adaptation planning, policymaking, and implementation is heavily dependent on how people perceive climate change risk and vulnerability [43]. This is also in line with the fact that institutions are known to view and manage risks differently [44] because of differences in societal organization. This then translates into differences in institutional cultures about how climate change risks should be recognized and what solutions to employ [45]. 
For effective implementation, when an alert is issued, it should be released to all stakeholders immediately. Ideally, these alerts should include a gauge of severity. They should also be tailored to specific groups in terms of geography, language, and livelihoods [39]. This is especially important considering that findings from the present study show that local language-based forecasts have led to a surge of interest among smallholder farmers. Alerts should also be specific in terms of timeframes of predictions together with uncertainty envelops. To reach the populations en masse, communication of alerts can be through the media or actors at all levels. Some information can be communicated through already existing visual tools such as electronic traffic dashboards. If these dashboards are used, links to more detailed information should ideally be provided.

\section{Conclusions}

Returning to the research question (i.e., which institutional support structures are currently being employed for climate disaster preparedness in the cereal value chain across Zambia?) set at the beginning of this study, it is now possible to state that while the government-led Farmer Input Support Programme (FISP) as the only strategy particularly targeted at disaster preparedness in the cereal value chain has merits, it is insufficient. Coping with associated challenges posed by floods and droughts in the cereal value chain requires an effective early warning and early action system (EWEAS) as opposed to waiting for disasters to affect vulnerable communities. Further, an EWEAS is best supplemented by longer-term sustainable strategies that can be implemented more broadly regardless of whether a forecast trigger is announced are necessary to lessen the pressure on having funding suddenly available. Such strategies could for instance involve delineating flood/drought risk areas and ensuring that cereal planted in these areas is favorable for the climate. Policies can also be developed that keep vulnerable communities without the capacity of coping with, e.g., floods from settling in flood-prone areas.

Therefore, to fully support the cereal value chain and realize food security in Zambia, an effective EWEAS is necessary. This study has also argued that since all EWEAS activities are based on the initial alert, investments in improving weather and climate forecasts are crucial. Based on these forecasts, institutional support before a disaster strikes can include rehabilitation of water points or construction of irrigation infrastructure. Vulnerable smallholder farmers can be trained on alternative agricultural practices and livelihood options or provided with access to drought-resistant seeds that would guarantee them a harvest in case of, e.g., a drought. Other activities applicable to both floods and droughts may include increased health service provision, extension services, food- and even cashbased safety nets.

Although this study considered all the main Agroecological Zones in Zambia, it is conceivable that future research lines can benefit from a larger pool of FDGs supplemented by surveys and individual interviews.

Funding: This research received no external funding.

Institutional Review Board Statement: The study was conducted according to the guidelines of the Declaration of Helsinki, and approved by the Institutional Review Board of the University of Potsdam (protocol code 810600 and date of approval 12 December 2020).

Informed Consent Statement: Informed consent was obtained from all subjects involved in the study.

Data Availability Statement: The data presented in this study are available on request from the corresponding author.

Acknowledgments: The author was supported by the Deutscher Akademischer Austauschdienst (DAAD; German Academic Exchange Service). Ngonga Chilekana is acknowledged for leading the data collection process and for reviewing the initial draft of this manuscript. Pertinent comments from two anonymous Reviewers, the Editor, Taylor Schildgen, Markus Seyfried, and the MPM 2020 of the University of Potsdam are also acknowledged.

Conflicts of Interest: The author declares no conflict of interest. 


\section{References}

1. FAO; ECA. Regional Overview of Food Security and Nutrition. Addressing the Threat from Climate Variability and Extremes for Food Security and Nutrition, Accra. 2018. 116p. Available online: https://www.fao.org/3/ca2710en/CA2710EN.pdf (accessed on 2 December 2020).

2. Madhumita, P. Food Insecurity in Southern Africa up 10\%. 2020. Available online: https://www.downtoearth.org.in/news/ africa/ food-insecurity-in-southern-africa-up-10-report-72575 (accessed on 9 July 2021).

3. IPCC. Climate Change: Synthesis Report. Contribution of Working Groups I, II and III to the Fifth Assessment Report of the Intergovernmental Panel on Climate Change; Core Writing Team, Pachauri, R.K., Meyer, L.A., Eds.; IPCC: Geneva, Switzerland, 2014.

4. Alexandratos, N.; Bruinsma, J. World Agriculture Toward 2030/2050: The 2012 Revision; ESA Working paper No 12-03; FAO: Rome, Italy, 2012.

5. FAO. Climate-Smart Agriculture. Policies, Practices and Financing for Food Security, Adaptation and Mitigation; FAO: Rome, Italy, 2010.

6. New, M.; Hewitson, B.; Stephenson, D.B.; Tsiga, A.; Kruger, A.; Manhique, A.; Gomez, B.; Coelho, C.A.; Masisi, D.N.; Kululanga, E.; et al. Evidence of trends in daily climate extreme climate events over southern and west Africa. J. Geophys. Res. Atmos. 2006, 111, D14102. [CrossRef]

7. Engelbrecht, C.; Engelbrecht, F.; Dyson, L. High-resolution model-projected changes in mid-tropospheric closed-lows and extreme rainfall events over southern Africa. Int. J. Climatol. 2012, 33, 173-187. [CrossRef]

8. ACAPS. Briefing Note: Floods. 2017. Available online: https://reliefweb.int/report/mozambique/acaps-briefing-note-floods-26 -january-2017 (accessed on 1 December 2020).

9. Smolka, A. Natural disasters and the challenge of extreme events: Risk management from an insurance perspective. Philos. Trans. R. Soc. A Math. Phys. Eng. Sci. 2006, 364, 2147-2165. [CrossRef] [PubMed]

10. Kunreuther, H. The role of insurance in reducing losses from extreme events: The need for public-private partnerships. Geneva Pap. Risk Insur. Issues Pract. 2015, 40, 741-762. [CrossRef]

11. Miglietta, P.P.; Porrini, D.; Fusco, G.; Capitanio, F. Crowding out agricultural insurance and the subsidy system in Italy: Empirical evidence of the charity hazard phenomenon. Agric. Financ. Rev. 2020, 82, 237-249. [CrossRef]

12. Pieterse, A.; Toit, J.; Niekerk, W. Climate change adaptation mainstreaming in the planning instruments of two South African local municipalities. Dev. South. Afr. 2020, 38, 493-508. [CrossRef]

13. UNDP. Real-Time Weather Forecasts are Helping Zambian Women Farmers Win Their Battle against the Impact of Climate Change. 2017. Available online: https:/ / www.adaptation-undp.org/real-time-weather-forecasts-are-helping-zambian-womenfarmers-win-their-battle-against-impact (accessed on 20 January 2021).

14. Chapoto, A.; Jayne, T.S. Zambian farmers' access to maize markets. Gates Open Res. 2019, 3, 1168. [CrossRef]

15. Knoema. Zambia-Land under Cereal Production. 2018. Available online: https://knoema.com/atlas/Zambia/Land-undercereal-production (accessed on 20 July 2021).

16. FAO. Global Information and Early Warning System on Food and Agriculture. 2019. Available online: http://www.fao.org/ giews/en (accessed on 12 August 2021).

17. Hichambwa, M.; Jayne, T.S. Agricultural Commercialization and Landholding Size in Zambia's Small-and Medium-Scale Farm Sector; FSRP Working Paper, Forthcoming; Food Security Research Project: Lusaka, Zambia, 2011.

18. IPC. Zambia: Acute Food Insecurity Projection Update February-March 2021. 2021. Available online: http://www.ipcinfo.org/ ipc-country-analysis / details-map/en/c/1153193/?iso3=ZMB (accessed on 29 July 2021).

19. FAO. GIEWS Country Brief: Zambia. 2021. Available online: http://www.fao.org/giews/countrybrief/country/ZMB/pdf/ ZMB.pdf (accessed on 20 June 2021).

20. Libanda, B.; Zheng, M.; Ngonga, C. Spatial and temporal patterns of drought in Zambia. J. Arid. Land 2019, 11, 180-191. [CrossRef]

21. Makondo, C.; Thomas, D. Seasonal and intra-seasonal rainfall and drought characteristics as indicators of climate change and variability in Southern Africa: A focus on Kabwe and Livingstone in Zambia. Theor. Appl. Climatol. 2020, 140, 271-284. [CrossRef]

22. ACAPS. Zambia Drought-Southern Province. 2019. Available online: https://reliefweb.int/sites/reliefweb.int/files/resources/ 20190711_acaps_start_briefing_note_drought_zambia_final.pdf (accessed on 12 December 2020).

23. ReliefWeb. Zambia: Prolonged Drought Increases Food Insecurity. 2020. Available online: https://reliefweb.int/report/zambia/ zambia-prolonged-drought-increases-food-insecurity (accessed on 12 August 2021).

24. Mwenda, M. The Drought in Zambia is Causing Starvation, a Power Crisis and Threatening the Victoria Falls. 2019. Available online: https:/ / www.lifegate.com/drought-in-zambia-starvation-kariba-victoria-falls (accessed on 12 August 2021).

25. OCHA. Zambia: Prolonged Drought Increases Food Insecurity. 2020. Available online: https://www.unocha.org/story/zambiaprolonged-drought-increases-food-insecurity (accessed on 12 August 2021).

26. IPCC. Climate Change: The Scientific Basis; Contribution of Working Group 1 to the Third Assessment Report of the Intergovernmental Panel on Climate Change; Houghton, J.T., Ding, Y., Griggs, D.J., Noguer, M., van der Linden, P.J., Dai, X., Maskell, K., Johnson, C.A., Eds.; Cambridge University Press: Cambridge, UK; New York, NY, USA, 2001.

27. Hughes, S. A meta-analysis of urban climate change adaptation planning in the U.S. Urban Clim. 2015, 14, 17-29. [CrossRef]

28. Mubaya, C.P.; Mafongoya, P. The role of institutions in managing local level climate change adaptation in semi-arid Zimbabwe. Clim. Risk Manag. 2017, 16, 93-105. [CrossRef]

29. Xu, Z.; Shi, L.; Wang, Y.; Zhang, J.; Huang, L.; Zhang, C.; Liu, S.; Zhao, P.; Liu, H.; Zhu, L.; et al. Pathological findings of COVID-19 associated with acute respiratory distress syndrome. Lancet Respir. Med. 2020, 8, 420-422. [CrossRef] 
30. Galvin, R. How many interviews are enough? Do qualitative interviews in building energy consumption research produce reliable knowledge? J. Build. Eng. 2015, 1, 2-12. [CrossRef]

31. Dworkin, S.L. Sample size policy for qualitative studies using in-depth interviews. Arch. Sex. Behav. 2012, 41, 1319-1320. [CrossRef] [PubMed]

32. Wang, B.; Pan, S.Y.; Ke, R.Y.; Wang, K.; Wei, Y.M. An overview of climate change vulnerability: A bibliometric analysis based on Web of Science database. Nat. Hazards 2014, 74, 1649-1666. [CrossRef]

33. Kuteya, A.N.; Jayne, T.S. Is the Government of Zambia's Subsidy to Maize Millers Benefiting Consumers? by Indaba Agricultural Policy Research Institute (IAPRI). Working Paper. 2012. Available online: http:/ / www.aec.msu.edu/fs2/zambia/index.htm (accessed on 12 August 2021).

34. Anríquez, G.; Daidone, S.; Mane, E. Rising food prices and undernourishment: A cross-country inquiry. Food Policy 2013, 38, 190-202. [CrossRef]

35. Chilufya, W.; Mulendema, N. Beyond Maize: Exploring Agricultural Diversification in Zambia. International Institute for Environment and Development. 2019. Available online: https://www.iied.org/beyond-maize-exploring-agricultural-diversificationzambia (accessed on 12 December 2020).

36. Musonda, B.; Jing, Y.; Iyakaremye, V.; Ojara, M. Analysis of long-term variations of drought characteristics using standardized precipitation index over Zambia. Atmosphere 2020, 11, 1268. [CrossRef]

37. IFRC. African Floods. 2021. Available online: https://reliefweb.int/sites/reliefweb.int/files/resources/IB11052021.pdf (accessed on 25 August 2021).

38. Suarez, P.; Tall, A. Towards Forecast-Based Humanitarian Decisions: Climate Science to Get from Early Warning to Early Action; Humanitarian Futures Programme: London, UK, 2010.

39. Red Cross, Early Warning-Early Action: Mechanisms for Rapid Decision Making. Drought Preparedness and Response in the Arid and Semi-Arid Lands of Ethiopia, Kenya, Uganda, and in the East African Region. 2009. Available online: http://www.climatecentre.org/downloads/IFRC_climate_risk_management_ewea_july_09.pdf\%5Cnhttp:/ / www.climatecentre. org/downloads/File/ewea_an_evaluation_of_ifrc_west_and_central_africa.pdf\%5Cnhttp://www.climatecentre.org/downloads / File/reports/EarlyWarning (accessed on 24 January 2021).

40. Patnaik, U.; Das, P.K.; Bahinipati, C.S. Coping with Climatic Shocks: Empirical Evidence from Rural Coastal Odisha India. Glob. Bus. Rev. 2016, 17, 161-175. [CrossRef]

41. Rossel, J.D. The Impact of Climatic Shocks on Child Nutrition in Peru; Young Lives Student Paper: Oxford, UK, 2008; pp. 1-38.

42. Matsueda, M.; Nakazawa, T. Early warning products for severe weather events derived from operational medium-range ensemble forecasts. Meteorol. Appl. 2015, 22, 213-222. [CrossRef]

43. McNeeley, S.; Lazrus, H. The Cultural Theory of Risk for Climate Change Adaptation. Weather. Clim. Soc. 2014, 6, 506-519. [CrossRef]

44. Rayner, S. Cultural Theory and Risk Analysis. Social Theories of Risk; Krimsky, S., Golding, D., Eds.; Praeger: Westport, CT, USA, 1992; pp. 83-115.

45. Thompson, M.; Rayner, S. Cultural Discourses. The Societal Framezork; Human Choice and Climate Change; Rayner, S., Malone, E.L., Eds.; Battelle Press: Harpenden, UK, 1998; Volume 1, pp. 265-343. 